\section{Summary}

1) The electromotive force of the cell $\mathrm{Th}(\mathrm{S}) / \mathrm{ThCl}_{4}-\mathrm{NaCl}(\mathrm{L}) / \mathrm{Cl}_{2}$ (g) was measured in the ranges of 0.2 mole fraction of $\mathrm{ThCl}_{4}$ at $630^{\circ} \mathrm{C} \sim 720^{\circ} \mathrm{C}$ and $0.3 \sim 0.7$ at $600^{\circ} \mathrm{C} \sim 700^{\circ} \mathrm{C}$.

2) The cell reaction can be regarded as $\mathrm{Th}(\mathrm{S})+2 \mathrm{Cl}_{2}(\mathrm{~g})=\mathrm{ThCl}_{4}(\mathrm{~L})$ by the fact that the extrapolated value from the measured curve is not very much different from the values calculated from thermodynamic data, and that the $\mathrm{Th}^{4+}$ ion is more stable than that of other valences of thorium.

3) The excess stability shows the existence of a compounds, the structure of which is in accordance with that indicated by thermal analysis, that is $\mathrm{Na}_{2} \mathrm{ThCl}_{6}$.

4) The large deviation from ideal state may be due to the formation of a complex ion such as $\left[\mathrm{ThCl}_{6}\right]^{2-}$ in the melt.

\section{Literatuers}

1) P. Drossbach, Z. Electrochem. 63, 516 (1959).

2) J.O.M. Bockris, Ann. N.Y. Acad. Sci. 79 Art 11803 (1960).

3) R. Oyamada, Master Thesis of T.I.T. in 1961.

4) K. Tanii, Denki Kagaku 32, 167 (1964).

5) A. Glassner, ANL 5750 (1957).

6) R. Srinivasan and S.N. Flengas, Can. J. Chem. 42, 1315 (1964).

7) M.V. Smironov and L. E. Ivanovski, $Z h$. Fiz. Khim 31, 641 (1952).

8) S.L. Darken, “Text Book for Memorial Lecture Meeting on the 10th Aniversary of the Foundation of National Research Institute for Metals."

\title{
Studies on the Anodic Dissolution of Silver in a LiCl-KCl Eutectic Melt*
}

\author{
Syukuji Asakur a and Takashi Mukaibo
}

Department of Industrial Chemistry, Faculty of Engineering, University of Tokyo, Bunkyo-ku, Toky

Received Dec. 23 (1966)

1) Theoretical treatments are made on the anodic dissolution of silver in the $\mathrm{LiCl}-\mathrm{KCl}$ eutectic melt. The main results are:

i) When anodic polarization is small, electrode process is controlled by diffu- 
sion or convective diffusion in a nonsteady and a steady state, respectively.

ii) When the polarization is very intense, migration controls the process in a steady state and current (i) obeys the following equations.

$$
\mathrm{i}=\mathrm{k}\left(\mathrm{V}-\psi_{\mathrm{s}}\right)
$$

where $\mathrm{k}, \mathrm{V}$ and $\psi_{\mathrm{s}}$ are a constant, the applied potential and E.M.F. of the cell, $\mathrm{Ag} / \mathrm{AgCl} / \mathrm{LiCl}-\mathrm{KCl}-\mathrm{AgCl} / \mathrm{Ag}$, respectively.

2) The experiments were performed as follows. The mixture of $\mathrm{LiCl}, \mathrm{KCl}$ and $\mathrm{AgCl}$ was dehydrated by passing dry $\mathrm{HCl}$ gas. The electrode system consisted of a microelectrode ( $\mathrm{Ag}$ point), a reference electrode ( $\mathrm{Ag}$ wire) and a couter electrode (Ag plate). The potentiostat, which responds to $50 \mathrm{kc} / \mathrm{sec}$., was employed and the response was recorded by a high speed pen recorder or a syncroscope.

3) The experimental results coincided with theoretical presumptions. The classification of dissolution mechanism at a constant potential was made on the potential-time plane.

\section{Introduction}

Elucidation of the electrode processes in molten salts has begun recently.1) According to the results obtained so far, electrode processes in halide melts have the following characteristics.

i) The activation overpotential is small. ii) When a metal is dissolved anodically, it is possible that the electrode surface is covered with its pure halide.

Piontelli and his coworkers $\left.{ }^{2} \sim 4\right)$ and Sternberg et al.5),6). investigated anodic and cathodic behaviors of various metals in their molten halides. Takahashi et al. 7) studied anodic behaviors of metals in the $\mathrm{LiCl}-\mathrm{KCl}$ eutectic melt.

In the present paper, as the initial step, theoretical analysis are made on the anodic behaviors of $\mathrm{Ag}$ electrode in the $\mathrm{LiCl}-\mathrm{KCl}$ eutectic melt.

As the next step, the above theories are ascertained by means of rapid methods which eliminate the change of electrode condition. Especially, two kinds of measuring method, "Two-points method" and "Differential method", are employed.

\section{Theory}

\subsection{Assumptions and Conditions}

Theoretical treatments are carried out on the following assumptions and conditions.

i) The concentrations of $\mathrm{Cl}^{-}, \mathrm{Ag}^{+}, \mathrm{K}^{+}$ and $\mathrm{Li}^{+}$are represented by $\mathrm{C}_{\mathrm{n}}(\mathrm{n}=$ $0,1,2,3) . \quad C_{0}$, the concentration of $\mathrm{Cl}^{-}$, is uniform even in the vicinity of electrode.

There is no flow of $\mathrm{Cl}^{-}$in the direction perpendicular to the electtrode $\left(\mathrm{j}_{\mathrm{o}}=0\right)$.

ii) Experimental temperature is above the melting point of $\mathrm{AgCl}$.

iii) Activation overpotential is neglected.

iv) $\mathrm{Ag}$ equlibrated with $\mathrm{Ag}^{+}$in bulk solution is used as the reference electrode, whose potential is defined as zero. Therefore, "Electrode potential" means the potential difference between the microelectrode and the reference electrode.

\subsection{Derivations of equations for the steady-state condition}

Under steady-state condition, $\mathrm{C}_{\mathrm{n}}$ is assumed to be the bulk concentration $\mathrm{C}_{\mathrm{n}}{ }^{\mathrm{b}}$ at the distance $\delta$ from electrode surface. The flux of charged species is expressed 
by Nernst-Planck's equation.

$$
\begin{aligned}
& \mathrm{j}_{\mathrm{n}}=F D_{n} C_{n} E / R T-D_{n} \partial C_{n} / \partial x \\
& (n=1,2,3)
\end{aligned}
$$

Where, $\mathrm{x}$; distance from electrode surface,

$\mathrm{D}_{\mathrm{n}}$; diffusion coefficient of n'th ions, $\mathrm{j}_{\mathrm{n}}$; flux per unit area of n'th ions, E. strength of electric field which is assumed to be constant through the reagion $\mathrm{O}<\mathrm{x}<\delta$

Under the steady-state condition, only $\mathrm{Ag}^{+}$flows and ions of $\mathrm{K}^{+}$or $\mathrm{Li}^{+}$do not. Accordingly,

$$
\mathrm{j}_{\mathrm{n}}=0 \quad(\mathrm{n}=2,3)
$$

The solution of Eq.(1) and (2) is

$$
\mathrm{C}_{\mathrm{n}}(\mathrm{x})=\mathrm{C}_{\mathrm{n}}{ }^{\mathrm{b}} \exp \{\mathrm{FE}(\mathrm{x}-\delta) / \mathrm{RT}\} \text { (3) }
$$

where $C_{n}$ b is the bulk concentration of $\mathrm{K}^{+}$or $\mathrm{Li}^{+}$. The condition of Electroneutrality leads to the relation.

$$
\sum_{n=1}^{3} C_{n}(x)=C_{0}(x)=C_{0} b=\sum_{n=1}^{3} C_{n} b
$$

Thus the distribution of $\mathrm{Ag}^{+}$is expressed by the equation

$$
\left.\mathrm{C}_{1}(\mathrm{x})=\mathrm{C}_{1_{\mathrm{o}}} \mathrm{b}-\left(\mathrm{C}_{\mathrm{o}}^{\mathrm{b}}-\mathrm{C}_{1} \mathrm{~b}\right) \exp \mathrm{FE}(\mathrm{x}-\delta) / \mathrm{RT}\right\}
$$

On the other hand, applied potential V is equal to the sum of the concentration overpotential $\psi$ and the ohmic drop $\phi$.

$$
\mathrm{V}=\psi+\phi
$$

$\psi$ and $\phi$ are represented as follows.

$$
\begin{aligned}
\psi & =\frac{\mathrm{RT}}{\mathrm{F}} \ln \gamma^{\mathrm{o}} \mathrm{C}_{1}(\mathrm{o}) / \gamma \mathrm{C}_{1} \mathrm{~b} \\
\phi & =\mathrm{E} \delta+\mathrm{iR}
\end{aligned}
$$

where $\gamma$ is the activity coefficient of $\mathrm{Ag}^{+}$, $\mathrm{R}$ is the resistance of solution between $\mathrm{x}=\delta$ and reference electrode and $\mathrm{i}$ is the current. Therefore, $\mathrm{R}$ depends on the position of refrence electrode. Combining the relations of (1) and (5), $i$ is expressed by Eq. (9).

$$
\mathrm{i}=\mathrm{F}^{2} \mathrm{D}_{1} \mathrm{C}_{\mathrm{o}} \mathrm{b} \mathrm{AE} / \mathrm{RT}=\mathrm{K}_{1} \mathrm{AE}
$$

where $\mathrm{A}$ is the surface area of electrode and $\mathrm{K}_{1}=\mathrm{F}^{2} \mathrm{D}_{1} \mathrm{C}_{\mathrm{o}} \mathrm{b} / \mathrm{RT}$.

-From Eqs.(8) and (9),

$$
\phi=\left(\delta+\mathrm{K}_{1} \mathrm{RA}\right) \mathrm{E}=\mathrm{rE}
$$

$r$ means the effective thickness of layer through which potential drops.

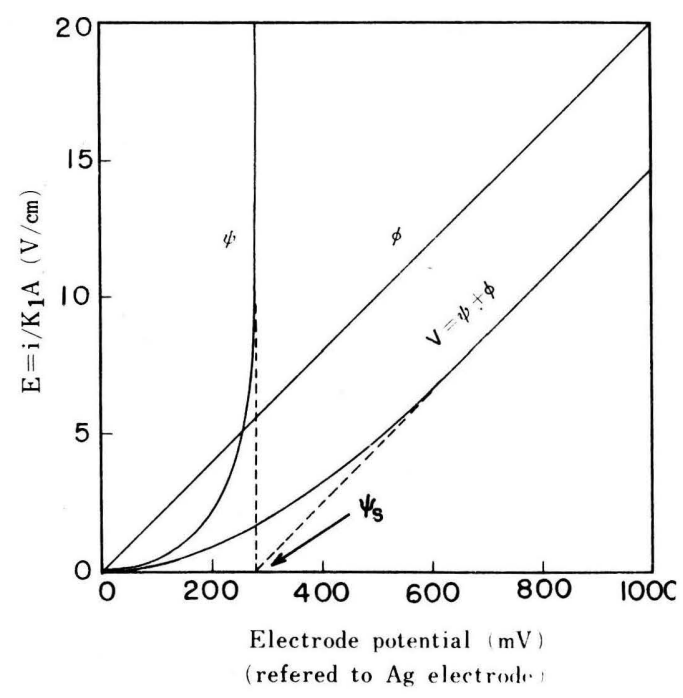

Fig. 1 Relation of E, $\phi, \psi$ and V.

Fig. I shows the relations between $\mathrm{E}$ or $\mathrm{i}$ and $\psi, \phi$ and $\mathrm{V}$, when $\mathrm{r}=0.05 \mathrm{~cm}$, $\delta=0.01 \mathrm{~cm}, \mathrm{C}_{\mathrm{o}} \mathrm{b} / \mathrm{C}_{1} \mathrm{~b}=100, \gamma^{\mathrm{o}} / \gamma^{\mathrm{b}}=1$ and $\mathrm{T}=723^{\circ} \mathrm{K}$.

a) Cases where $\mathrm{V}$ is sufficiently large. $\mathrm{C}_{1}(\mathrm{o})$ and $\psi$ approach $\mathrm{C}_{\mathrm{o}} \mathrm{b}$ and $\psi_{\mathrm{s}}$ respectively, as $\mathrm{V}$ becomes larger.

$$
\psi_{\mathrm{s}}=\mathrm{RT} / \mathrm{F} \ln \gamma^{\mathrm{o}} \mathrm{C}_{\mathrm{o}} \mathrm{b} / \gamma^{\mathrm{b}} \mathrm{C}_{1} \mathrm{~b}
$$

The open-circuit potential $\left(\mathrm{V}_{\mathrm{p}}\right)$ immediatly after the cutting-off of current tends to $\psi_{\mathrm{s}}$ as $\mathrm{V}_{\mathrm{o}}$ increases. The $\mathrm{V}$-i relation is

$$
\mathrm{i}=\mathrm{K}_{1} \mathrm{~A}\left(\mathrm{~V}-\psi_{\mathrm{s}}\right) / \mathrm{r}
$$

It is difficult to ascertain Eq.(12) directly from the measurements because $r$ varies as the dissolution proceeds. However, two kinds of method described below make it possible to confirm Eq.(12) indirectly.

Two points of $(\mathrm{V}, \mathrm{i})$ in steady-states are measured in succesion and a straight line passing through these two points is extrapolated to $\mathrm{i}=0$. From the intersection with $x$-axis, $\psi_{\mathrm{s}}$ is obrained. We call this method as "Two-points method". The other is "Differential method". First, a constant potential $V_{0}$ is added to the 
electrode. After the current reacnes a stationary value, a sweep voltage $(\mathrm{dV})$ is superimposed on $V_{0}$. The di/dV gives the differential conductance. Thus the extrapolation of the tangent to $\mathrm{i}=0$ yields $\psi_{\mathrm{s}}$ (see Fig. 7(b) and (c)).

(b) The cases where $\mathrm{V}$ is small.

In this case the relation of $\psi \approx \mathrm{V}$ and $\gamma^{\mathrm{o}} \approx \gamma^{\mathrm{b}}$ holds. If the limitation of $\mathrm{E}$ $\ll \mathrm{RT} / \mathrm{F}$ and $\mathrm{C}_{\mathrm{O}} \mathrm{b} \gg \mathrm{C}_{1} \mathrm{~b}$ are added to the above relation, $\mathrm{i}$ is given by Eq. (13) approximately.

$$
\mathrm{i}=\mathrm{FAD}_{1} \mathrm{C}_{1} \mathrm{~b} \delta^{-1}[\exp (\mathrm{FV} / \mathrm{RT})-1]
$$

Eq. (13) agrees with the equation derived from the assumption that ions move near an electrode by only diffusion. ${ }^{8)}$

\subsection{Non-steady state}

In order to obtain $\mathrm{C}_{\mathrm{n}}$ as a function of $\mathrm{x}$ and $\mathrm{t}$, the partial differential equation (14) must be solved with the condition of Eq. (15).

$$
\begin{aligned}
& \partial \mathrm{C}_{\mathrm{n}} / \partial \mathrm{t}=\mathrm{D}_{\mathrm{n}} \frac{\partial}{\partial \mathrm{x}}\left(\mathrm{FEC}_{\mathrm{n}} / \mathrm{RT}-\partial \mathrm{C}_{\mathrm{n}} / \partial \mathrm{x}\right) \\
& \mathrm{V}=\frac{\mathrm{RT}}{\mathrm{F}} \ln \left\{\gamma^{\circ} \mathrm{C}_{1}(\mathrm{o}, \mathrm{t}) / \gamma^{\mathrm{b}} \mathrm{C}_{1}^{\mathrm{b}}\right\}+\mathrm{r}^{\prime} \mathrm{E}
\end{aligned}
$$

Where r' means the effective thickness of layer through which potential drops at a certain instance. Although it is difficult to obtain the general solution of Eq. (14), it is possible to get the relations between $\mathrm{V}, \mathrm{i}$ and $\mathrm{t}$ in some limiting cases.

a) $i$ at an instance of imposition of $V_{o}$ Initial conditions in this case are

$$
\begin{aligned}
& V=0 \text { and } C_{n}(x, t)=C_{n} b \text { for } t<0 . \\
& V=V_{o} \text { and } C_{n}(x, t)=C_{n} \text { b for } t=0 .
\end{aligned}
$$

Thus, the first term of (15) is eliminated.

$$
\mathrm{V}_{\mathrm{o}}=\kappa \mathrm{ARE}=\mathrm{iR}
$$

Where $\kappa$ and $\mathrm{R}$ are the specific conductivity and the resistance of the solution, respectively,

b) The case where migration is negligible

In this case, the diffusion equation with regard to $\mathrm{C}_{1}$ well describes the movement of $\mathrm{Ag}^{+}$

$$
\partial \mathrm{C}_{1} / \partial_{\mathrm{t}}=\mathrm{D}_{1} \partial^{2} \mathrm{C}_{1} / \partial \mathrm{x}^{2}
$$

Since the second term of Eq. (15) can be eliminated and the relation $\gamma^{0} \approx \gamma^{\mathrm{b}}$ holds when $\mathrm{V}$ is much smaller than $\psi_{\mathrm{s}}$, the initial conditions are;

$$
\begin{aligned}
& \mathrm{C}_{1}(\mathrm{x}, \mathrm{t})=\mathrm{C}_{1}{ }^{\mathrm{b}} \text { for } \mathrm{t}<0, \\
& \mathrm{C}_{1}(\mathrm{O}, \mathrm{t})=\mathrm{C}_{1}{ }^{\mathrm{b}} \exp \left(\mathrm{FV}_{\mathrm{o}} / \mathrm{RT}\right) \text { for } \mathrm{t} \geqq 0
\end{aligned}
$$

The boundary condition is;

$$
\mathrm{C}_{1}(\infty, \mathrm{t})=\mathrm{C}_{1} \mathrm{~b}
$$

The solution of Eq. (17) is given by Eq. (20).

$$
\begin{aligned}
& C_{1}(x, t)=C_{1} b\left[1+\left\{\exp \left(F_{o} / R T\right)-1\right\}\right. \\
& \left.\operatorname{erfc} x / 2 \sqrt{\left.D_{1} t\right)}\right]
\end{aligned}
$$

Application of Fick's first law to (20) gives the equation for current response.

$$
\begin{aligned}
& \mathrm{i}=\mathrm{FA} \sqrt{\mathrm{D}_{1}} \mathrm{C}_{1} \mathrm{~b} / \exp \left(\mathrm{FV}_{\mathrm{o}} / \mathrm{RT}\right)-1 ; / \\
& \sqrt{\pi \mathrm{t}}
\end{aligned}
$$

\section{Experimental}

The electrolyte is composed of the LiCl-KCl eutectic melt containing 1.0 $\mathrm{mol} \% \mathrm{AgCl}$. Because $\mathrm{LiCl}$ can not be desiccated completely only by means of heating and evacuation, the bath was treated by the following procedure.

$\mathrm{LiCl}, \mathrm{KCl}$ and $\mathrm{AgCl}$ were weighed and mixed in the air. The mixture was put in the cell made of Telex glass and dried by heating in vacuum up to $200^{\circ} \mathrm{C}$.

Between $200^{\circ} \mathrm{C}$ and the melting 
point, dry $\mathrm{HCl}$ gas was passed through the system.

After the mixture was melted, the system was evacuated again for a few hours in order to remove $\mathrm{HCl}$ gas dissolved in the bath. After these treatments, dry $\mathrm{N}_{2}$ gas was introduced into the system and measurements were carried out.

The electrode system consisted of a microelectrode, a reference electrode and a counter electrode. The microelectrode was a $0.5 \mathrm{~mm} \phi \mathrm{Ag}$ wire sealed in a glass tube and polished so that a section of $\mathrm{Ag}$ wire was exposed. The $\mathrm{Ag}$ wire and $\mathrm{Ag}$ plate were used as a reference and a counter electrode, respectively. The potentiostat, which responds to $50 \mathrm{kc} / \mathrm{sec}$ was employed to set the voltage between the reference electrode and the microelectrode. The response was recorded by a high speed pen recorder or a syncroscope. The electrical furnance was onoff controlled to maintain the temperature within $\pm 2{ }^{\circ} \mathrm{C}$. The distance between the microelectrode and the reference electrode was about $1 \mathrm{~cm}$ but not fixed precisely because the accurate distance was not required.

\section{Results}

\subsection{Anodic Dissolution at a Con- stant Potential}

4.1.1 Outline of current response In order to obtain the outline of the dissolution mechanism. the current change with time was measured at a constant potential $\mathrm{V}_{\mathrm{o}}$ of the microelectrode. The plot of $(\log \mathrm{t}, \log \mathrm{i})$ is given in Fig. 2, where $i_{p}$ is the current at $t=0$.

The relationship between $i_{p}$ and $V_{o}$ is shown in Fig. 3. $i_{p}$ was measured in such a short period as the electrode did not change so much. Fig. 3 proves that the relation (16), i. e. ohmic relation, is

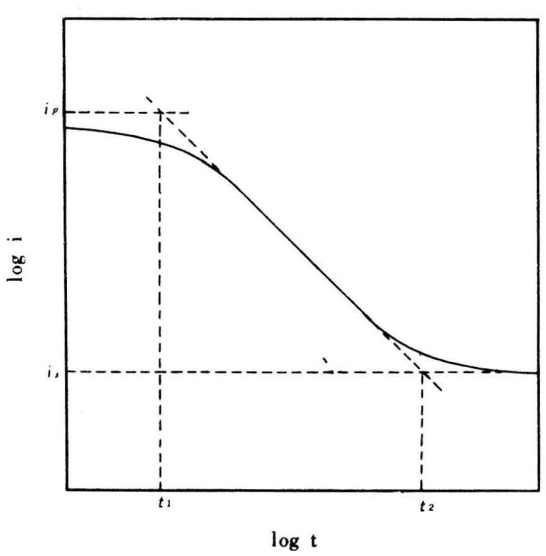

Fig. 2 Schematic current-time curve.

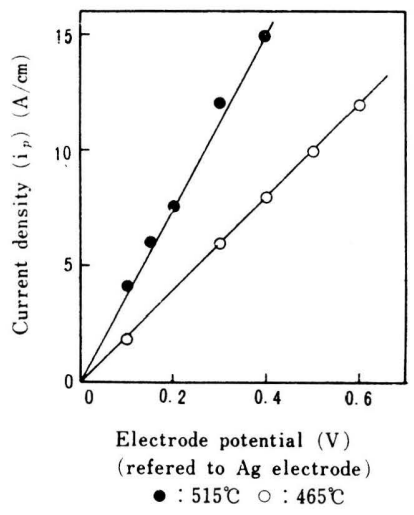

Fig. 3 Relation between $V_{o}$ and $i_{p}$.

fulfilled. In the interval of $0<\mathrm{t}<\mathrm{t}_{1}$, the system behaves pseudo-capacitive. In other words, current decays exponentially with time from $i_{p}$ and its amplitude is proportional to $\mathrm{V}_{0}$. For the interval $\mathrm{t}_{1}<\mathrm{t}<\mathrm{t}_{2}$, $\mathrm{i}$ is expressed by (22) experimentally.

$$
\mathrm{i}=\mathrm{K} \cdot \mathrm{t}^{-}
$$

$\mathrm{K}$ is determined by the position and condition of the electrode and is not constant in the course of the experiments because the electrode surface goes on dissolving.

However, $t_{1}, t_{2}$ and $f$ in Fig. 2 depend not on the electrode condition but on $V_{o}$ only. Thus, $t_{1}, t_{2}$ and $f$ are given 


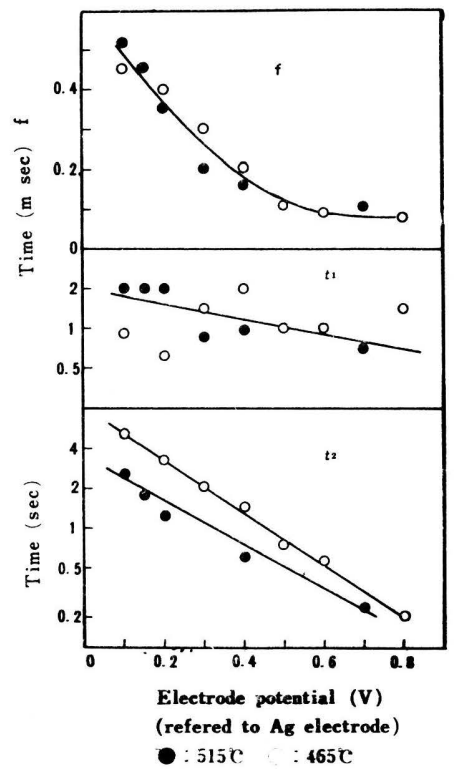

Fig. 4 Dependence of $f, t_{1}, t_{2}$ on $V$.

in Fig. 4 as the function of $V_{0}$. It is seen in Fig. 2 that $f$ approaches 0.5 as $\mathrm{V}_{\mathrm{o}}$ becomes small. The value of 0.5 for $\mathrm{f}$ means that diffusion controls the electrode process.

$t_{1}$ and $t_{2}$ were about 1 msec. and 1 sec., respectively and both decreased with $\mathrm{V}_{\mathrm{o}}$. $\mathrm{i}_{\mathrm{s}}$ decayed slowly as the dissolution of electrode proceeded.

\subsubsection{Two-points method for high} potential As shown in Fig. 4, above $500 \mathrm{mV}$ i reached a steady value within 1 sec. So the current at $1 \mathrm{sec}$. was adopted as a steady value. Measurements were made for the two sets of potentials; $500 \mathrm{mV} \sim 1000 \mathrm{mV}$ and $700 \mathrm{mV} \sim 1500 \mathrm{mV}$. This fact accords with the theory derived in 2.1 .

4.1.3 The current response to low potential $i \propto t^{1 / 2}$ was already proved for a small potential step in a nonsteady state. Then, the dependence of $i$ on $V_{o}$

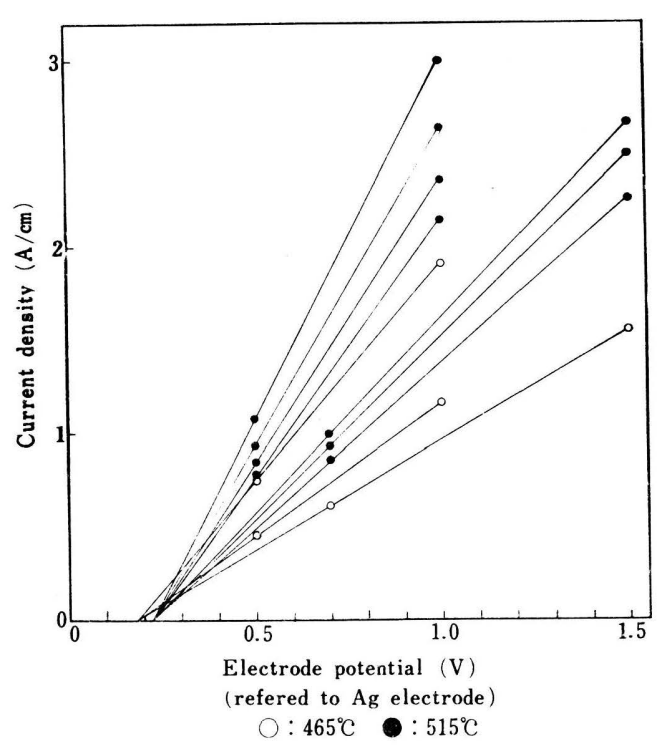

Fig. 5 Two-points method.

at a constant time was observed.

According to Fig. 4, the response is in a transient state within $1 \mathrm{sec}$. below

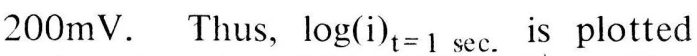
against $\log \left\{\exp \left(\mathrm{FV}_{0} / \mathrm{RT}\right)-1\right\}$ in Fig. 6 (1) and (2).

Fig. 6 shows that $(i)_{t=1}$ sec. is proportional to $\left[\exp \left(\mathrm{FV}_{\mathrm{O}} / \mathrm{RT}\right)-1\right]$ and $\mathrm{Eq}$. (25) well holds. The values of $D_{1}$, which was yielded by inserting the experimental data into Eq. (25), were $1.5 \times 10^{-5}$ $\mathrm{cm}^{2} / \mathrm{sec}$. at $465^{\circ} \mathrm{C}$ and $2.9 \times 10^{-5}$ $\mathrm{cm}^{2} / \mathrm{sec}$. at $515^{\circ} \mathrm{C}$.

These values agree fairly well with the data obtained by the chronopotentiometric measurements (for example, $2.7 \times$ $10^{-5} \mathrm{~cm}^{2} / \mathrm{sec}$. at $450^{\circ} \mathrm{C}$ ). In a steady state, when $\mathrm{V}_{\mathrm{o}}$ was small, fairly reproducible results were obtained since the surface area of the electrode did not change so much because of the small dissolution rate. Line (3) in Fig. 6 shows an example of the plot of $\log \mathrm{i}$ vs $\log \left[\exp \left(\mathrm{FV}_{\mathrm{o}} / \mathrm{RT}\right)\right.$ $-1]$. 


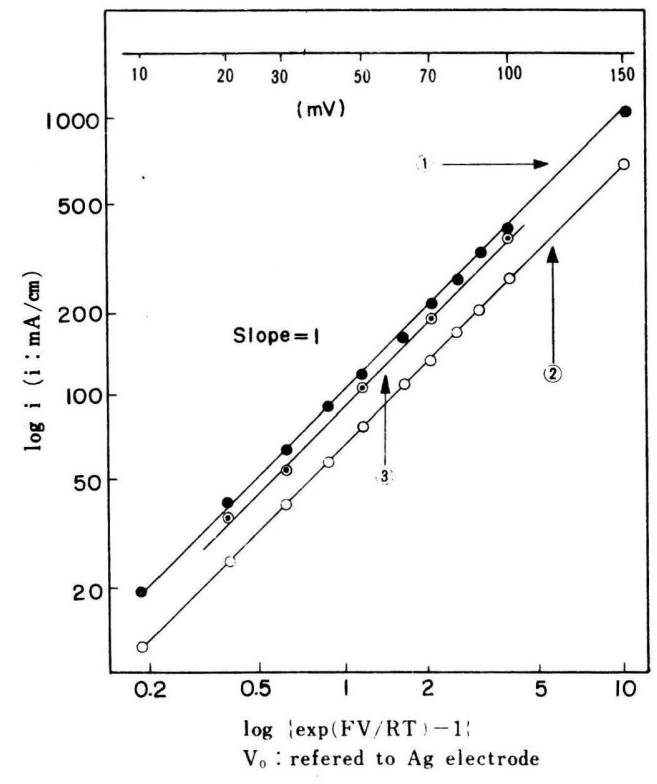

Fig. 6 Plot of $\log$ i vs. $\log \{\exp (\mathrm{FV} / \mathrm{RT})-1\}$ for small electrode potential.

The steady current is proportional to $\left[\exp \left(\mathrm{FV}_{\mathrm{o}} / \mathrm{RT}\right)-1\right]$ and obeys Eq. (13).

Insertion of experimental values to Eq. (13) gives the value of $\delta$ of about $10^{-2} \mathrm{~cm}$.

This thickness is considered to be about the same order as the thickness of diffusion layer.

\subsection{Potential Sweep Experiments}

The sweep signal $(60 \mathrm{mV} / \mathrm{sec}$.) generated by means of a simple C-R integrator was fed to the potentiostat to control the electrode potential.

\subsubsection{The case where potential sweep} was started from zero A schematic current-time or a current-potential deagram is presented in Fig. 7(a).

The curve becomes straight when potential exceeds $300 \mathrm{mV}$ and its slope becomes smaller again as the potential increases still more because the dissolu-
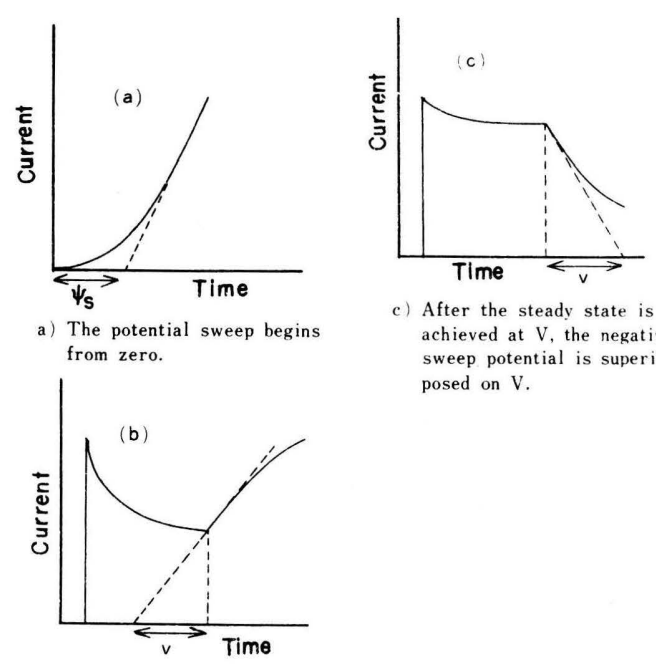
achieved at $\mathrm{V}$, the negative sweep potential is superim. posed on $\mathrm{V}$.

Fig. 7 Illustration of potential sweep experiment.

tion of the electrode changes its state. The linear portion of the curve, which is presumed to represent Eq. (12), is extrapolated to $\mathrm{i}=0$ in order to obtain $\psi_{\mathrm{s}}$.

The actual values of $\psi_{\mathrm{s}}$ are $180 \sim 190$ $\mathrm{mV}$ at $465^{\circ} \mathrm{C}$ and $195 \sim 200 \mathrm{mV}$ at $515^{\circ} \mathrm{C}$. These values well agree with those obtained by the two-points method.

\subsubsection{Differential method After} current reached a steady value at a constant potential $V_{0}$, the positive or negative sweep voltage were superposed on $V_{0}$. The current varied as is shown in Fig. $7(\mathrm{~b})$ and (c). $\psi_{\mathrm{s}}$, derived in the manner similar to 4.2.1 and plotted in Fig. 8, has the limiting values which are 210 $220 \mathrm{mV}$ at $515^{\circ} \mathrm{C}$ and $195 \sim 205 \mathrm{mV}$ at $465^{\circ} \mathrm{C}$.

\subsection{Electrode Potential $\left(\mathrm{V}_{\mathrm{p}}\right)$ Imme- diately after the Cutting off of Current}




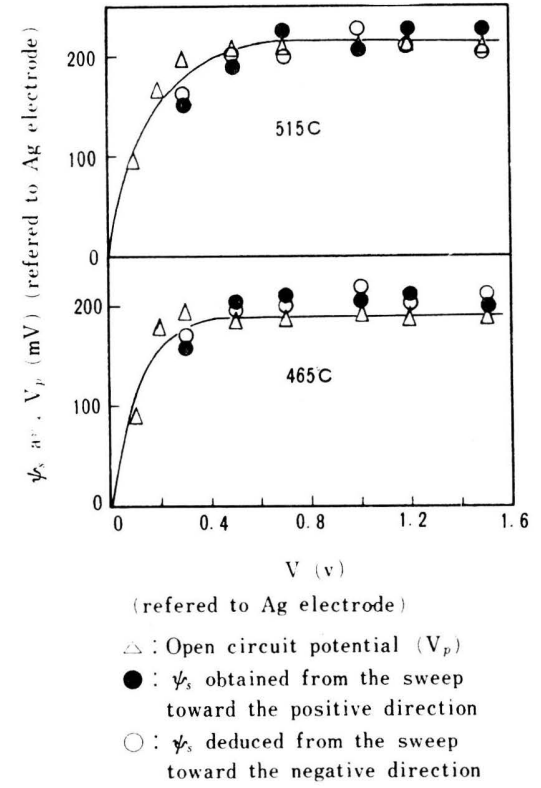

Fig. 8 Open circuit potential $\left(\mathrm{V}_{\mathrm{p}}\right)$ and $\psi_{\mathrm{s}}$ obtained from differential method.

$V_{p}$ was measured after the current responding to a step potential reached a steady value. Fig. 8 shows the data. $V_{p}$ approaches the constant values about 210 $\mathrm{mV}$ at $515^{\circ} \mathrm{C}$ and $180 \sim 190 \mathrm{mV}$ at $465^{\circ} \mathrm{C}$ as $\mathrm{V}_{\mathrm{o}}$ increases.

\subsection{Application of the Potential having Alternating Component}

The potential consisting of D.C. component $\mathrm{V}_{\mathrm{o}}$ and A.C. component $\Delta \mathrm{V}$ was given to the electrode for the purpose of investigating the phase difference between $\Delta \mathrm{V}$ and the alternating component of responding current $\Delta \mathrm{i} . \Delta \mathrm{V}$ was given in the form of sine wave having the frequency of $1000 \mathrm{c} / \mathrm{sec}$ and the amplitude of $100 \mathrm{mV}$. It was observed that the phase shift became zero and ohmic property appeared in cases where $V_{0}$ exceeded $200 \mathrm{mV}$ both at $465^{\circ} \mathrm{C}$ and at $515^{\circ} \mathrm{C}$.

This fact suggests that Eq. (12) well holds for the large value of $\mathrm{V}_{\mathrm{o}}$.

\section{Discussion}

\subsection{Dissolution Mechanism when a Large Potential was Applied}

The values of $\psi_{\mathrm{s}}$ obtained by these various experiments and the theoretical values calculated are listed in Table 1. Though the observed values appear slightly smaller than the calculated ones, agreements are fairly good.

Table 1. $\psi_{\mathrm{s}}$ Obtained by Various Methods

\begin{tabular}{l|c|c}
\hline $\begin{array}{l}\text { Method } \\
\text { of Measurement }\end{array}$ & $515^{\circ} \mathrm{C}$ & $465^{\circ} \mathrm{C}$ \\
\hline Theoretical value & $236 \mathrm{mV}$ & $222 \mathrm{mV}$ \\
Open circuit potential & 210 & $180 \sim 190$ \\
Two-points method & $220 \sim 230$ & $180 \sim 190$ \\
Potential sweep method & $195 \sim 200$ & $180 \sim 190$ \\
Differential method & $210 \sim 220$ & $190 \sim 205$ \\
\hline
\end{tabular}

The reason for the deviation from the theoretical values is considered to be the increase in the concentration of $\mathrm{Ag}^{+}$ due to the corrosion of $\mathrm{Ag}$, because it is assumed in the theoretical treatments that the bulk concentration of $\mathrm{Ag}^{+}$is always constant. Actually, chemical analysis of the bath after the experiment showed the increase of $\mathrm{Ag}^{+}$to some extent. It is concluded that, when the electrode potential exceeds $\psi_{\mathrm{s}}$, its surface is covered with pure $\mathrm{AgCl}$ and the current obeys Eq. (12).

Accordingly, $\left(\partial \mathrm{C}_{1} / \partial \mathrm{x}\right)_{\mathrm{x}}=0$ is nearly zero owing to Eq. (5). These conclusions were further confirmed by the experiments in 4.4 .

\subsection{Dissolution Mechanism when Small Potential is applied}

Current obeys Eq. (13) in nonsteady 
state and Eq. (21) in steady state. The respective state may be mentioned as diffusion control or convective diffusion control.

\subsection{Classification of Dissolution Me- chanism}

The dissolution mechanism of $\mathrm{Ag}$ at constant potentials can be classified as in Fig. 9. Domain (1) in Fig. 9 is the one

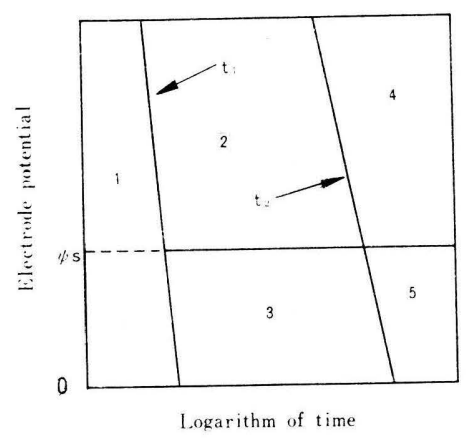

Fig. 9 Classification of dissolution mechanism at constant potential electrolysis.

where the system is pseudo-capacitive and is electrically equivalent to a C-R series circuit. In domain (2), diffusion and migration take place in a nonsteady and complicated manner.

In domains (3), (4) and (5)', the electrode processes are controlled by diffusion, migration and convective diffusion, respectively. Domain (3) corres- ponds to Eq. (21), (4) to Eq. (12) and (5) to Eq. (13).

\section{Acknowledgment}

The authers express their deep gratitude to Asistant Prof. Kazuo Fueki of Tokyo University for his suggestive discussions.

\section{Literatuers:}

1) M. Blander, "Molten Salt Chemistry" p. 681 (1964), Interscience Publishers, New York.

2) R. Piontelli, B. Rivoita, G. Montatelli, Z. Elektrochem. 59, 64 (1955).

3) R. Piontelli, G. Sternheim, M. Francini, $J$. Chem. Phys. 24, 1113 (1956).

4) R. Piontelli, G. Sternheim, J. Chem. Phys. 23, 1971 (1955).

5) S. Sternberg, D. I. Marchidan, Z. physik. Chem. 218, 250(1961).

6) I. G. Murgulescu, S. Sternberg, L. Medititev, D. Mustetea, Electrochim. Ac. S. 65 (1963).

7) M. Takahashi, Y. Amada, Denki-Kagaku, 32140 (1964).

8) T. Mukaibo, S. Asakura, Yoyuen, 8606 (1965).

9) H. A. Laitinen., W. Ferguson, Anal Chem. 29, 4 (1957).

10) M. Takahashi, Denki-Kagaku, 25432 (1957). 